\title{
OPEN A phase II study of the safety of olanzapine for oxaliplatin based chemotherapy in coloraectal patients
}

Junichi Nishimura ${ }^{1 凶}$, Akiko Hasegawa², Toshihiro Kudo², Tomoyuki Otsuka², Masayoshi Yasui ${ }^{1}$, Chu Matsuda ${ }^{1}$, Naotsugu Haraguchi ${ }^{1}$, Hajime Ushigome ${ }^{1}$, Nozomu Nakai ${ }^{1}$, Tomoki Abe ${ }^{1}$, Hisashi Hara ${ }^{1}$, Naoki Shinno ${ }^{1}$, Kei Asukai ${ }^{1}$, Shinichiro Hasegawa ${ }^{1}$, Daisaku Yamada ${ }^{1}$, Keijiro Sugimura ${ }^{1}$, Kazuyoshi Yamamoto ${ }^{1}$, Hiroshi Wada ${ }^{1}$, Hidenori Takahashi ${ }^{1}$, Takeshi Omori ${ }^{1}$, Hiroshi Miyata ${ }^{1}$ \& Masayuki Ohue ${ }^{1}$

Olanzapine has exhibited efficacy as an antiemetic agent when used with $5-\mathrm{HT}_{3}$ receptor antagonists, dexamethasone, and $\mathrm{NK}_{1}$ receptor antagonists for patients receiving highly emetogenic chemotherapy. In addition, several studies have reported the efficacy or safety of olanzapine in patients receiving moderately emetogenic chemotherapy, including carboplatin, irinotecan, and oxaliplatin. However, no reports of olanzapine use have focused on patients receiving oxaliplatinbased chemotherapy. Therefore, we analyzed the safety of antiemetic therapy using olanzapine, palonosetron, aprepitant, and dexamethasone in colorectal cancer patients undergoing oxaliplatinbased chemotherapy. This study was a prospective phase II single-institution study of 40 patients (median age 60 years, 23 patients were male). The primary endpoint was the incidence of adverse events, and the exploratory endpoints were the rate of chemotherapy-induced nausea and vomiting. Almost all patients $(90 \%)$ had a performance status of 0 . All patients received the scheduled antiemetic therapy. The most common adverse event was somnolence $(n=7$ patients, $17.5 \%$ ). All adverse events were grade 1 . Thirty-six patients were included in the exploratory analysis of efficacy. No patients experienced vomiting during the first $120 \mathrm{~h}$ after chemotherapy, and complete response and complete control were both $86.1 \%$. The rate of total control was $55.6 \%$ during the same time period. Olanzapine use with $5-\mathrm{HT}_{3}$ receptor antagonists, dexamethasone, and $\mathrm{NK}_{1}$ receptor antagonists was safe for colorectal cancer patients receiving oxaliplatin-based chemotherapy.

Chemotherapy-induced nausea and vomiting (CINV) are common adverse events of cancer chemotherapy. Previously, we reported a non-blinded, randomized, controlled phase 3 study (SENRI trial) that explored the efficacy of an antiemetic regimen of 5-hydroxytryptamine type $3\left(5-\mathrm{HT}_{3}\right)$ receptor antagonists, dexamethasone, and neurokinin-1 ( $\left.\mathrm{NK}_{1}\right)$ receptor antagonists for colorectal cancer patients receiving oxaliplatin-based chemotherapy ${ }^{1,2}$. The rate of vomiting was significantly reduced in the aprepitant group that received $5-\mathrm{HT}_{3}$ receptor antagonists, dexamethasone, and $\mathrm{NK}_{1}$ receptor antagonists. We also reported a subgroup analysis for the SENRI trial; we found gender to be a risk factor for vomiting and nausea. However, in the SENRI trial, the rate of no nausea and no vomiting without rescue medication was $58.3 \%$, which is still low, in the first $120 \mathrm{~h}$ after chemotherapy. To reduce CINV during oxaliplatin-based chemotherapy, new agents can be added to the 5- $\mathrm{HT}_{3}$ receptor antagonists, dexamethasone, and $\mathrm{NK}_{1}$ receptor antagonists.

Olanzapine is an antipsychotic agent that blocks multiple neurotransmitters, including dopamine at D1, D2, D3, and D4 receptors; serotonin at 5-HT type 2a, 5-HT type 2c, 5- $\mathrm{HT}_{3}$, and 5-HT type 6 receptors; catecholamines at alpha1-adrenergic receptors; acetylcholine at muscarinic receptors; and histamine at $\mathrm{H} 1$ receptors in the central nervous system. Since Passik et al. first reported the pilot study of olanzapine as antiemetic therapy ${ }^{3}$, work has focused on olanzapine activity as an antiemetic agent.

${ }^{1}$ Department of Gastroenterological Surgery, Osaka International Cancer Institute, 3-1-69 Otemae, Chuo-ku, Osaka, Osaka 541-8567, Japan. ${ }^{2}$ Department of Clinical Oncology, Osaka International Cancer Institute, 3-1-69 Otemae, Chuo-ku, Osaka 541-8567, Japan. ${ }^{\circledR}$ email: jnishimura@gesurg.med.osaka-u.ac.jp 
Several studies have reported that regimens including olanzapine are better than triplet-combination regimens (5- $\mathrm{HT}_{3}$ receptor antagonists, dexamethasone, and $\mathrm{NK}_{1}$ receptor antagonists $)^{4-6}$. The guidelines established by the American Society of Clinical Oncology (ASCO) and National Comprehensive Cancer Network (NCCN) recommend olanzapine with the triplet-combination therapy against highly emetogenic chemotherapy (HEC) regimens ${ }^{7,8}$.

For moderately emetogenic chemotherapy (MEC), a small randomized control trial has reported the effects of olanzapine as an antiemetic agent in addition to $5-\mathrm{HT}_{3}$ receptor antagonists, dexamethasone, and $\mathrm{NK}_{1}$ receptor antagonists. They could not confirm the efficacy of olanzapine at the acute phase of emesis because of a small sample size and did not focus on a regimen including oxaliplatin ${ }^{5}$. In this phase 2 study, we assessed the safety of antiemetic treatment using olanzapine, $5-\mathrm{HT}_{3}$ receptor antagonists, dexamethasone, and $\mathrm{NK}_{1}$ receptor antagonists. We also explored the rate of CINV in patients receiving oxaliplatin-based chemotherapy.

\section{Patients and methods}

Eligibility criteria. This study is registered at UMIN Clinical Trials Registry (number UMIN 000032591). The study included oxaliplatin-naïve patients with colorectal cancer who were 20 years of age or older and received FOLFOX (oxaliplatin $85 \mathrm{mg} / \mathrm{m}^{2}$, levo-leucovorin $200 \mathrm{mg} / \mathrm{m}^{2}$, and fluorouracil $400 \mathrm{mg} / \mathrm{m}^{2}$ bolus and $2400 \mathrm{mg} / \mathrm{m}^{2}$ continuous infusion) or XELOX (capecitabine $2000 \mathrm{mg} / \mathrm{m}^{2}$ orally on days 1-14 and oxaliplatin $130 \mathrm{mg} / \mathrm{m}^{2}$ via intravenous infusion on day 1). Molecular targeted therapy was allowed. Neoadjuvant chemotherapy, recurrent/unresectable chemotherapy, and adjuvant chemotherapy were included in this study. Institutional review boards approved the study protocol, and written informed consent was obtained from all participants before enrollment.

Exclusion criteria. Patients were excluded if they had nausea or vomiting within $24 \mathrm{~h}$ prior to enrollment, were treated with antiemetics within $24 \mathrm{~h}$ prior to treatment, had any factors causing nausea or vomiting (e.g., gastrointestinal obstruction or symptomatic brain metastasis), had uncontrollable diabetes, were pregnant or lactating or planning on becoming pregnant, or were currently receiving pimozide.

Treatment protocol. All patients received oral aprepitant $(125 \mathrm{mg})$ plus an intravenous 5- $\mathrm{HT}_{3}$ receptor antagonist (palonosetron hydrochloride) and dexamethasone $(6.6 \mathrm{mg})$ on day 1, and aprepitant ( $80 \mathrm{mg})$ and oral dexamethasone ( $2 \mathrm{mg}$ ) twice daily on days 2 and 3. Olanzapine (5 mg) was administered after dinner for 4 days from the first day of oxaliplatin administration.

Patient evaluation. The study period was only the first cycle of oxaliplatin-based chemotherapy. Patients recorded their response in a diary daily for 5 days. The use of rescue therapy, defined as any medication taken to treat nausea and vomiting, was also recorded. The severity of nausea was classified into four grades: 0 , none; 1 , mild; 2, moderate; or 3, severe. No nausea and mild nausea were considered as no significant nausea. For vomiting, patients recorded the frequency. Retches were also included as vomiting ${ }^{1}$. An emetic episode was defined as single or multiple emetic vomiting experiences occurring within an interval of $5 \mathrm{~min}$. It was also subjectively assessed by each patient.

Statistical analysis. The primary endpoint was the incidence of grade 3 or 4 adverse events. Thirty-two patients were required to achieve $80 \%$ statistical power with a one-sided $\alpha$ error of 0.05 assuming an expected adverse event rate of $1 \%$ and a threshold of $10 \%$. An arc-sine transformation was performed with the binomial test for the required sample sizes calculation ${ }^{9}$. The planned sample size was 40 patients for enrollment after taking dropouts into consideration. The exploratory endpoint was the rate of no vomiting, no nausea, no significant nausea (defined as none or mild nausea), complete response (defined as no vomiting episode and no rescue therapy), complete control (defined as no vomiting, no rescue therapy, and no significant nausea), and total control (no vomiting, no rescue therapy, and no nausea) in the acute (first $24 \mathrm{~h}$ after chemotherapy), delayed (24-120 h after chemotherapy), and overall phases (0-120 h after chemotherapy). We calculated $95 \%$ confidence intervals (CIs) for the proportion of patient characteristics and CINV. Adverse events were graded using Common Toxicity Criteria for Adverse Events, version 4.0. Alcohol use was divided into two groups: drinker, patient has drinking habit every day, and light/non-drinker for others. Statistical analyses were performed using JMP software version 13 (SAS Institute, Cary, NC, USA). The estimation of sample size was carried out in R version 4.0.2.

Ethical approval. All procedures involving human participants were performed in accordance with the ethical standards of the institutional and/or national research committee and with the 1964 Helsinki declaration and its later amendments or comparable ethical standards. This study was approved by the Institutional Review Board of Osaka International Cancer Center (approval no. 18015) and was registered at UMIN Clinical Trials Registry (number UMIN000032591) on 15/05/2018.

\section{Results}

Forty patients (age range 36-80 years; 23 males) were enrolled in this study between March 2018 and April 2019. Patient characteristics are provided in Table 1 . The median age was 60 years ranged 36 to 80 years. The male was $23(58 \%)$. Most patients had a performance status of 0 . Twelve patients (30\%) received FOLFOX regimen, and 28 patients (70\%) received the CAPOX regimen. The use of molecular target drug was in 13 patients (33\%). The previous colon resecton surgery was done in 30 patients (83\%). Ileostomy was underwent in 4 patients (11\%), and colostomy in 3 patients $(8 \%)$. Only 1 patient $(3 \%)$ received chemotherapy previously. The reason of chemotherapy 


\begin{tabular}{|c|c|}
\hline Characteristic & All patients $(n=40)$ \\
\hline Median age, years (IQR) & $60(53-66)$ \\
\hline Sex, male & $23(58,42-71)$ \\
\hline \multicolumn{2}{|l|}{ Ethnicity, n (\%) } \\
\hline Asian & $40(100)$ \\
\hline \multicolumn{2}{|l|}{ Performance status } \\
\hline 0 & $36(90,77-96)$ \\
\hline 1 & $3(8,3-20)$ \\
\hline 2 & $1(3,0.4-13)$ \\
\hline \multicolumn{2}{|l|}{ Chemotherapy regimen } \\
\hline FOLFOX & $12(30,18-45)$ \\
\hline CAPOX & $28(70,55-82)$ \\
\hline \multicolumn{2}{|l|}{ Use of molecular target drug } \\
\hline Yes & $13(33,20-48)$ \\
\hline \multicolumn{2}{|l|}{ Colorectal resection } \\
\hline Yes & $34(85,71-93)$ \\
\hline \multicolumn{2}{|l|}{ Stoma } \\
\hline Ileostomy & $5(13,5-26)$ \\
\hline Colostomy & $3(8,3-20)$ \\
\hline \multicolumn{2}{|l|}{ Purpose of chemotherapy } \\
\hline Neoadjuvant treatment & $2(5,1-17)$ \\
\hline Adjuvant treatment & $19(48,33-63)$ \\
\hline Metastatic disease & $19(48,33-63)$ \\
\hline \multicolumn{2}{|l|}{ Smoking history } \\
\hline Never & $19(48,33-63)$ \\
\hline Ex-smoker & $21(52,37-67)$ \\
\hline \multicolumn{2}{|l|}{ Alcohol use } \\
\hline Light/non-drinker & $30(75,60-86)$ \\
\hline Drinker & $10(25,14-40)$ \\
\hline History of vomiting during pregnancy & $8(47,26-69)$ \\
\hline History of motion sickness & $5(13,5-26)$ \\
\hline
\end{tabular}

Table 1. Patient characteristics. $I Q R$ interquartile range. Data are given as $n(\%$, confidence interval) unless otherwise noted.

\begin{tabular}{|l|l|}
\hline Event & $\mathbf{n}(\mathbf{\%}, \mathbf{C I})$ \\
\hline Anorexia & $14(35,22-50)$ \\
\hline Somnolence & $7(17.5,9-32)$ \\
\hline Constipation & $1(2.5,0.4-13)$ \\
\hline Diarrhea & $1(2.5,0.4-13)$ \\
\hline Malaise & $1(2.5,0.4-13)$ \\
\hline Hematological toxicity & $0(0.0,0-9)$ \\
\hline Hepatotoxicity & $0(0.0,0-9)$ \\
\hline Nephrotoxicity & $0(0.0,0-9)$ \\
\hline
\end{tabular}

Table 2. Adverse events in the study population. CI 95\% confidence interval. All adverse events were Grade 1.

was preoperative neoadjuvant chemotherapy in 2 patients (5\%), postoperative adjuvant chemotherapy in 19 patients (48\%), and chemotherapy for unresectable or recurrence tumor in 19 patients (48\%). Alcohol use was light or nondrinker in 30 patients (75\%) and drinker in 10 patients (25\%). History of vomiting during pregnancy was noted in 8 of 16 patients (50\%). History of motion sickness was observed in 5 patients (13\%).

Adverse events. All patients received the scheduled antiemetic treatment. The adverse events are given in Table 2. The most common adverse events were anorexia (35\%) and somnolence (17.5\%). All adverse events were grade 1 and were tolerated. We did not observe any adverse hematological events, and no treatment-related deaths were reported during this study. 


\begin{tabular}{|c|c|}
\hline Characteristic & All patients $(n=36)$ \\
\hline Median age, years (IQR) & $59(52-65)$ \\
\hline Sex, male & $20(56,40-70)$ \\
\hline \multicolumn{2}{|l|}{ Performance status } \\
\hline 0 & $33(92,78-97)$ \\
\hline 1 & $2(6,2-18)$ \\
\hline 2 & $1(3,0.5-14)$ \\
\hline \multicolumn{2}{|l|}{ Chemotherapy regimen } \\
\hline FOLFOX & $10(28,16-44)$ \\
\hline CAPOX & $26(72,56-84)$ \\
\hline \multicolumn{2}{|l|}{ Use of molecular target drug } \\
\hline Yes & $12(33,20-50)$ \\
\hline \multicolumn{2}{|l|}{ Colorectal resection } \\
\hline Yes & $30(83,68-92)$ \\
\hline \multicolumn{2}{|l|}{ Stoma } \\
\hline Ileostomy & $4(11,4-25)$ \\
\hline Colostomy & $3(8,3-22)$ \\
\hline \multicolumn{2}{|l|}{ Purpose of chemotherapy } \\
\hline Neoadjuvant treatment & $2(6,2-18)$ \\
\hline Adjuvant treatment & $18(50,34-66)$ \\
\hline Metastatic disease & $16(44,30-60)$ \\
\hline \multicolumn{2}{|l|}{ Smoking history } \\
\hline Never & $17(47,32-63)$ \\
\hline Ex-smoker & $19(53,37-68)$ \\
\hline \multicolumn{2}{|l|}{ Alcohol use } \\
\hline Light/non-drinker & $28(78,62-88)$ \\
\hline Drinker & $8(22,12-38)$ \\
\hline History of vomiting during pregnancy & $8(50,28-72)$ \\
\hline History of motion sickness & $5(14,6-29)$ \\
\hline
\end{tabular}

Table 3. Characteristics of patients included in the CINV analysis. IQR interquartile range. Data are given as $\mathrm{n}$ (\%, confidence interval) unless otherwise noted.

\begin{tabular}{|l|l|l|l|}
\hline Phase & Acute \% (CI) & Delayed \% (CI) & Overall \% (CI) \\
\hline No vomiting & $100(90-100)$ & $100(90-100)$ & $100(90-100)$ \\
\hline No nausea & $97.2(86-100)$ & $61.1(45-75)$ & $61.1(45-75)$ \\
\hline No significant nausea & $100(90-100)$ & $94.4(82-98)$ & $94.4(82-98)$ \\
\hline Complete response & $100(90-100)$ & $86.1(71-94)$ & $86.1(71-94)$ \\
\hline Complete control & $100(90-100)$ & $86.1(71-94)$ & $86.1(71-94)$ \\
\hline Total control & $97.2(86-100)$ & $55.6(40-70)$ & $55.6(40-70)$ \\
\hline
\end{tabular}

Table 4. Efficacy analysis in 36 patients. CI 95\% confidence interval.

Efficacy. Thirty-six patients recorded their responses in the diary. Four patients forgot to record the patient diary. Thus, 36 of the 40 patients were included in the analysis of efficacy (Table 3). None of the patients experienced vomiting in the acute, delayed, or overall phases (Table 4). Five patients (14\%) used rescue antiemetic therapy. Only 2 patients $(6 \%)$ who had significant nausea used rescue antiemetic therapy. The proportions of patients with each outcome in each phase are given in Table 3. No nausea in the acute, delayed, and overall phase was noted in $97.2 \%, 61.1 \%$, and $61.1 \%$ of patients, respectively.

\section{Discussion}

In this study, we analyzed the safety of olanzapine as an antiemetic agent with 5- $\mathrm{HT}_{3}$ receptor antagonists, dexamethasone, and $\mathrm{NK}_{1}$ receptor antagonists for colorectal cancer patients undergoing oxaliplatin-based chemotherapy. The incidence of somnolence was $17.5 \%$, and the patients suffered no grade 2 or greater adverse events. We also analyzed the rate of CINV. None of the patients experienced vomiting, and a complete response occurred in $86.1 \%$ of patients in the delayed and overall phases. To the best of our knowledge, this report is the first to analyze the safety and efficacy of adding olanzapine to triple antiemetic therapy in oxaliplatin-based chemotherapy. 
In HEC regimens, several studies have shown the efficacy of olanzapine. Navari et al. first reported the efficacy of adding olanzapine to dexamethasone and granisetron ${ }^{4}$. They also reported the efficacy of olanzapine combined with an $\mathrm{NK}_{1}$ receptor antagonist, a 5- $\mathrm{HT}_{3}$ receptor antagonist, and dexamethasone ${ }^{10}$. The FOND-O trial reported the efficacy of adding olanzapine to fosaprepitant, ondansetron, and dexamethasone in patients undergoing HEC and hematopoietic transplantation ${ }^{11}$. Recently, Hashimoto et al. assessed adding olanzapine to aprepitant, palonosetron, and dexamethasone in patients receiving cisplatin-based chemotherapy ${ }^{6}$.

For MEC regimens, only one small randomized trial has evaluated the efficacy of olanzapine with palonosetron and dexamethasone, without $\mathrm{NK}_{1}$ receptor antagonist. Their study did not meet the primary endpoint of complete response, but the rate of significant nausea was significantly reduced in the olanzapine-treated group. Tanaka et al. reported a phase II study of the addition of olanzapine to antiemetic therapy with aprepitant, a 5 -HT3 receptor antagonist, and dexamethasone in patients receiving chemotherapy including carboplatin ${ }^{12}$. In their study, the complete response rate in the overall phase was $93.9 \%$, compared to $86.1 \%$ in the present study. In the SENRI trial, which was a non-blinded randomized trial, the complete response rate of patients treated with $\mathrm{NK}_{1}$ receptor antagonist, a 5- $\mathrm{HT}_{3}$ receptor antagonist, and dexamethasone was $85.0 \%$. It was not possible to unconditionally compare the SENRI trial to this study; the number was small, evaluation was difficult, and we could not confirm the effectiveness of adding olanzapine determined by the complete response. Adding olanzapine may increase the complete response rate, which must be proven in a future phase III trial.

Several studies have investigated the efficacy and safety of $5 \mathrm{mg}$ olanzapine with an $\mathrm{NK}_{1}$ receptor antagonist, $5-\mathrm{HT}_{3}$ receptor antagonist, and dexamethasone in Japanese patients undergoing HEC ${ }^{13-15}$. A double-blind randomized phase II study suggested a recommended dose of $5 \mathrm{mg}$ olanzapine as an antiemetic agent ${ }^{15}$. Therefore, we administered $5 \mathrm{mg}$ olanzapine, not $10 \mathrm{mg}$, in this study. We did not note any severe adverse events, including somnolence. Thus, administration of $5 \mathrm{mg}$ olanzapine to $\mathrm{NK}_{1}$ receptor antagonist, palonosetron, and dexamethasone is a safe alternative to antiemetics for colorectal cancer patients treated with oxaliplatin-based chemotherapy.

In this study, we administered palonosetron, a second generation $5-\mathrm{HT}_{3}$ receptor antagonist characterized by a long plasma elimination half-life $(\sim 40 \mathrm{~h})$ and a high selective binding affinity for the $5-\mathrm{HT}_{3}$ receptor. Several studies have shown a superior antiemetic effect of palonosetron compared to other 5- $\mathrm{HT}_{3}$ receptor antagonists ${ }^{16-19}$. The efficacy of palonosetron relative to other $5-\mathrm{HT}_{3}$ receptor antagonists has been evaluated in a meta-analysis ${ }^{20}$, and the efficacy of the combination of $\mathrm{NK}_{1}$ receptor antagonist, palonosetron, and dexamethasone compared to other antiemetic regimens was evaluated recently in a meta-analysis ${ }^{21}$. The combination antiemetic therapy of $\mathrm{NK}_{1}$ receptor antagonist, palonosetron, and dexamethasone was superior in the delayed phase with MEC regimen, and the overall phase for HEC and MEC regimens. The TRIPLE study, a randomized, double-blind, phase III trial, revealed that the complete response in the delayed period was higher in patients using palonosetron than patients using granisetron ${ }^{22}$.

The present study has some limitations. First, it was a single-arm trial with limited sample size at a single institution. Second, we assessed the safety of olanzapine in patients receiving oxaliplatin-based chemotherapy, but the efficacy of this antiemetic regimen was unclear. Further comparative studies are needed to determine the efficacy.

In conclusion, administration of olanzapine with NK1 receptor antagonist, palonosetron, and dexamethasone is a safe alternative to antiemetics for colorectal cancer patients treated with oxaliplatin-based chemotherapy.

Received: 30 September 2020; Accepted: 5 February 2021

Published online: 25 February 2021

\section{References}

1. Nishimura, J. et al. Combination antiemetic therapy with aprepitant/fosaprepitant in patients with colorectal cancer receiving oxaliplatin-based chemotherapy (SENRI trial): A multicentre, randomised, controlled phase 3 trial. Eur. J. Cancer 51, 1274-1282. https://doi.org/10.1016/j.ejca.2015.03.024 (2015).

2. Takemoto, H. et al. Combination antiemetic therapy with aprepitant/fosaprepitant in patients with colorectal cancer receiving oxaliplatin-based chemotherapy in the SENRI trial: Analysis of risk factors for vomiting and nausea. Int. J. Clin. Oncol. 22, 88-95. https://doi.org/10.1007/s10147-016-1022-9 (2017).

3. Passik, S. D. et al. A pilot exploration of the antiemetic activity of olanzapine for the relief of nausea in patients with advanced cancer and pain. J. Pain Symptom Manag. 23, 526-532. https://doi.org/10.1016/s0885-3924(02)00391-3 (2002).

4. Navari, R. M. et al. A phase II trial of olanzapine for the prevention of chemotherapy-induced nausea and vomiting: A Hoosier Oncology Group study. Support. Care Cancer 13, 529-534. https://doi.org/10.1007/s00520-004-0755-6 (2005).

5. Jeon, S. Y. et al. A randomized, double-blind, placebo-controlled study of the safety and efficacy of olanzapine for the prevention of chemotherapy-induced nausea and vomiting (CINV) in patients receiving moderately emetogenic chemotherapy: Results of the Korean South West Oncology Group (KSWOG) Study. Cancer Res. Treat. https://doi.org/10.4143/crt.2017.577 (2018).

6. Hashimoto, H. et al. Olanzapine $5 \mathrm{mg}$ plus standard antiemetic therapy for the prevention of chemotherapy-induced nausea and vomiting (J-FORCE): A multicentre, randomised, double-blind, placebo-controlled, phase 3 trial. Lancet Oncol. 21, 242-249. https ://doi.org/10.1016/S1470-2045(19)30678-3 (2020).

7. Hesketh, P. J. et al. Antiemetics: American Society of Clinical Oncology clinical practice guideline update. J. Clin. Oncol. 35, 3240-3261. https://doi.org/10.1200/JCO.2017.74.4789 (2017).

8. NCCN. NCCN clinical practice guidelines in oncology version 2. Antiemesis. National Comprehensive Cancer Network (2020).

9. Nadelman, R. B. et al. Prophylaxis with single-dose doxycycline for the prevention of Lyme disease after an Ixodes scapularis tick bite. N. Engl. J. Med. 345, 79-84. https://doi.org/10.1056/NEJM200107123450201 (2001).

10. Navari, R. M. et al. Olanzapine for the prevention of chemotherapy-induced nausea and vomiting. N. Engl. J. Med. 375, 134-142. https://doi.org/10.1056/NEJMoa1515725 (2016).

11. Clemmons, A. B. et al. Randomized, placebo-controlled, phase III trial of fosaprepitant, ondansetron, dexamethasone (FOND) versus FOND plus olanzapine (FOND-O) for the prevention of chemotherapy-induced nausea and vomiting in patients with hematologic malignancies receiving highly emetogenic chemotherapy and hematopoietic cell transplantation regimens: The FOND-O Trial. Biol. Blood Marrow Transpl. 24, 2065-2071. https://doi.org/10.1016/j.bbmt.2018.06.005 (2018).

12. Tanaka, K. et al. Olanzapine-containing antiemetic therapy for the prevention of carboplatin-induced nausea and vomiting. Cancer Chemother. Pharmacol. 84, 147-153. https://doi.org/10.1007/s00280-019-03868-5 (2019). 
13. Abe, M. et al. Efficacy and safety of olanzapine combined with aprepitant, palonosetron, and dexamethasone for preventing nausea and vomiting induced by cisplatin-based chemotherapy in gynecological cancer: KCOG-G1301 phase II trial. Support. Care Cancer 24, 675-682. https://doi.org/10.1007/s00520-015-2829-z (2016).

14. Nakashima, K. et al. A phase II study of palonosetron, aprepitant, dexamethasone and olanzapine for the prevention of cisplatinbased chemotherapy-induced nausea and vomiting in patients with thoracic malignancy. Jpn. J. Clin. Oncol. 47, 840-843. https:// doi.org/10.1093/jjco/hyx084 (2017).

15. Yanai, T. et al. A double-blind randomized phase II dose-finding study of olanzapine $10 \mathrm{mg}$ or $5 \mathrm{mg}$ for the prophylaxis of emesis induced by highly emetogenic cisplatin-based chemotherapy. Int. J. Clin. Oncol. 23, 382-388. https://doi.org/10.1007/s10147-0171200-4 (2018).

16. Aapro, M. S. et al. A phase III, double-blind, randomized trial of palonosetron compared with ondansetron in preventing chemotherapy-induced nausea and vomiting following highly emetogenic chemotherapy. Ann. Oncol. 17, 1441-1449. https://doi. org/10.1093/annonc/mdl137 (2006).

17. Eisenberg, P., MacKintosh, F. R., Ritch, P., Cornett, P. A. \& Macciocchi, A. Efficacy, safety and pharmacokinetics of palonosetron in patients receiving highly emetogenic cisplatin-based chemotherapy: A dose-ranging clinical study. Ann. Oncol. 15, 330-337. https://doi.org/10.1093/annonc/mdh047 (2004).

18. Gralla, R. et al. Palonosetron improves prevention of chemotherapy-induced nausea and vomiting following moderately emetogenic chemotherapy: Results of a double-blind randomized phase III trial comparing single doses of palonosetron with ondansetron. Ann. Oncol. 14, 1570-1577. https://doi.org/10.1093/annonc/mdg417 (2003).

19. Saito, M. et al. Palonosetron plus dexamethasone versus granisetron plus dexamethasone for prevention of nausea and vomiting during chemotherapy: A double-blind, double-dummy, randomised, comparative phase III trial. Lancet Oncol. 10, 115-124. https ://doi.org/10.1016/S1470-2045(08)70313-9 (2009).

20. Popovic, M. et al. Efficacy and safety of palonosetron for the prophylaxis of chemotherapy-induced nausea and vomiting (CINV): A systematic review and meta-analysis of randomized controlled trials. Support. Care Cancer 22, 1685-1697. https://doi.org/10.1007/ s00520-014-2175-6 (2014)

21. Chow, R. et al. Efficacy of the combination neurokinin-1 receptor antagonist, palonosetron, and dexamethasone compared to others for the prophylaxis of chemotherapy-induced nausea and vomiting: A systematic review and meta-analysis of randomized controlled trials. Ann. Palliat. Med. 7, 221-233. https://doi.org/10.21037/apm.2018.03.09 (2018).

22. Suzuki, K. et al. Randomized, double-blind, phase III trial of palonosetron versus granisetron in the triplet regimen for preventing chemotherapy-induced nausea and vomiting after highly emetogenic chemotherapy: TRIPLE study. Ann. Oncol. 27, 1601-1606. https://doi.org/10.1093/annonc/mdw220 (2016).

\section{Author contributions}

All authors participated in the design of this study. A.H., T.K., and T.O. enrolled the patients to this study. J.N., and A.H. analyzed the data. J.N. drafted the manuscript. All authors reviewed the manuscript.

\section{Competing interests}

The authors declare no competing interests.

\section{Additional information}

Correspondence and requests for materials should be addressed to J.N.

Reprints and permissions information is available at www.nature.com/reprints.

Publisher's note Springer Nature remains neutral with regard to jurisdictional claims in published maps and institutional affiliations.

(c) (i) Open Access This article is licensed under a Creative Commons Attribution 4.0 International License, which permits use, sharing, adaptation, distribution and reproduction in any medium or format, as long as you give appropriate credit to the original author(s) and the source, provide a link to the Creative Commons licence, and indicate if changes were made. The images or other third party material in this article are included in the article's Creative Commons licence, unless indicated otherwise in a credit line to the material. If material is not included in the article's Creative Commons licence and your intended use is not permitted by statutory regulation or exceeds the permitted use, you will need to obtain permission directly from the copyright holder. To view a copy of this licence, visit http://creativecommons.org/licenses/by/4.0/.

(C) The Author(s) 2021 